In this article I analyze how and why, in the middle of the 1960's, the fashion advertising of the Rhodia Textile, introduce pioneering black models in their advertisings campaigns, as way of adding positive value to their brands. In the period, such integration is an exception to the rule, because the few times that blacks people appeared in advertisements produced in the country, occupied the space often stigmatized for the servants. To try to understand this decision, apparently out of step with market realities, I analysis from the studies on visual culture by Duby (1992), MAUAD (1966), and Barthes (1990); and consumption and advertising studies by MCCRACKEN (2003), FARIAS (2003) and FRY (2002), text and images that make up the advertising campaigns in major varieties and women's magazines then in circulation: Manchete, O Cruzeiro, Claudia e Jia. I also analyze the inclusion of black models in fashion editorials and advertising campaigns in the context of international fashion, and how it fosters the participation of black models in advertising of Rhodia Textile in Brazil.

Keywords: fashion models, advertising and fashion. 


\section{As modelos negras na publicidade de moda no Brasil dos anos 1960}

\section{Maria Claudia BONADIO}

Neste artigo analiso como e porque, em meados dos anos 1960, a publicidade de moda da Rhodia Têxtil introduz pioneiramente modelos negras em suas campanhas veiculadas na mídia impressa (editoriais de moda, reportagens e anúncios impressos) como forma de agregar caracteres positivos às suas marcas. No período, tal inserção é uma exceção à regra, pois nas poucas vezes em que os negros apareciam na publicidade produzida no país, ocupavam frequentemente o espaço estigmatizado destinado à criadagem. Para tentar entender essa decisão, em aparente descompasso com a realidade do mercado, analiso a partir dos estudos sobre cultura visual de DUBY (1992), MAUAD (1966), BARTHES (1990); consumo e publicidade de MCCRACKEN (2003), FARIAS (2003) e FRY (2002); texto e imagem que compõem as campanhas veiculadas nas principais revistas de variedades e femininas nacionais então em circulação: Manchete, O Cruzeiro, Claudia e Jia. Examino, ainda, porque a inserção das modelos negras em desfiles, editoriais e campanhas publicitárias no contexto da moda internacional, sobretudo nos Estados Unidos, a contar do momento em que se extingue a segregação racial, favorece a participação de modelos negras brasileiras em peças publicitárias da Rhodia Têxtil.

Palavras-chave: modelos negras, publicidade, moda. 


\section{As modelos negras e o mercado da moda}

Ninguém na SPFW é racista. A média de modelos negros por desfile é dois, para cerca de 40, mas a culpa é do mercado. "Mercado", aqui, é sujeito indeterminado (Folha de S. Paulo, domingo, 20 de janeiro de 2008).

Durante a realização da $24^{a}$ semana de moda de São Paulo (São Paulo Fashion Week), o jornalista Alcino Leite Neto realizou a contagem do número de modelos negras na passarela. Constatou que dos 344 modelos (homens e mulheres) que desfilaram nos dias 17 e 18 de janeiro de 2008, apenas 8 eram negros, menos de $2,3 \%$ do total. O dado causou polêmica e originou a abertura, pelo Ministério Público, de um inquérito para investigação da prática de racismo.

Entre os estilistas e donos de agências de modelos, sobraram acusações e faltaram explicações. Segundo reportagem da Folha de S. Paulo (20 de janeiro de 2008), os poucos estilistas que opinaram sobre o assunto reclamaram que o casting de modelos negras oferecido pelas agências é muito reduzido, fato que dificulta o acesso destas aos desfiles. O pessoal das agências replica: "o mercado não pede negro". "Cabelo liso é sempre mais requisitado", justifica Marcos Cunha, coordenador de new faces da Elite Models. "O número de negros que aparecem querendo ser modelo é bem menor [...] Eles não procuram tanto a carreira" diz Laura Vieira, da agência de modelos Ten (Folha de S. Paulo, idem) .

Em meio às divergências, a opinião mais convincente parece ser a do diretor de planejamento da agência de publicidade F/ Naszca, Fernan Alphen. Para ele, "no fundo, é preconceito puro e simples", sendo a palavra 'mercado' utilizada para justificar essa força oculta. O preconceito não é racial, é social: isola por medo do outro. O negro é supostamente mais pobre e, por isso, não tem acesso à informação, não tem gosto. "E, como a moda tem essa pretensão de divulgar tendência, ela quer fazê-lo entre a elite branca" (Folha de S. Paulo, idem).

Ana Carolina Oliveira entende que, nos dias atuais, o protagonismo das modelos negros restringe-se basicamente à Afromídia. Elas aparecem em peças publicitárias voltadas exclusivamen- 
te para o consumidor negro e campanhas de linhas de produtos étnicos, por exemplo, sabonetes e xampus (OLIVEIRA, 2007).

Na publicidade para o público em geral, especialmente a voltada para o mercado da moda, a pesquisadora sustenta que é possível observar basicamente dois tipos de situações. Uma ocorre quando a tríade empresa/estilista/veículo de comunicação se propõe a assumir atitudes politicamente corretas ante seu público-alvo, outra quando tem o intuito de despertar ou aprofundar a discussão da questão racial (OLIVEIRA, 2007).

Apesar das restrições, "nos últimos anos, as pessoas de cor tornaram-se mais numerosas na publicidade brasileira" e "abandonaram o papel estereotipado da criadagem para se tornarem profissionais em geral, quase cidadãos genéricos" (FRY, 2002, p. 303) '. Tal transformação resulta de um "fenômeno mercadológico, que busca o lucro se baseando em parâmetros culturais" (FRY, op. cit., pp. 311-313) que refletem as lutas do movimento negro contra a discriminação racial. Ela decorre também da ampliação da visibilidade do potencial de consumo dos negros brasileiros desde meados dos anos 1990. Peter Fry acrescenta, no entanto, que a despeito dos inúmeros avanços sociais alcançados, as maiores responsáveis pela ampliação da visibilidade dos negros na publicidade contemporânea continuam a ser as peças e campanhas publicitárias produzidas para a Afromídia.

Independentemente da oferta de modelos negras pelas agências de publicidade e mesmo diante da sensível ampliação da participação de negros em comerciais de diversos produtos, há indícios inequívocos de que continua a existir resistência do mercado em trazê-las para a publicidade. Tanto nos editoriais de moda como nos anúncios de margarina, a participação de negros ainda é restrita, periférica mesmo, e está longe de refletir o percentual da população negra no país².

Os estudos sobre a visibilidade do negro na mídia concordam que o principal responsável por sua parca participação é o preconceito de "marca", que incide sobre a aparência (traços físicos como o formato e tipo de cabelo e a coloração da pele) e a consequente associação de tais traços a uma situação econômica e social desfavorável (SCHWARCZ, 2000). A interação entre o preconceito e a condição socioeconômica desfavorável restrin- 
ge drasticamente a presença do negro na publicidade, capas de revistas ou telenovelas (Sobre esse tema ver: BELELI, 2006; FRY, 2002 e ARAÚJO, 2004).

Tentemos, agora, entender um paradoxo.

Há que se concordar que "o mercado é o divulgador mais eficiente de conceitos e idéias no Brasil contemporâneo" (FRY, op. cit., p. 305) e a publicidade pode ser entendida como "uma espécie de extrato simbólico de um certo tipo de pensamento social" (FARIAS, 2003, p. 211), razões que, ainda em nossos dias, apequenam a participação de modelos negros no mercado publicitário.

Em meados dos anos 1960 tal situação era ainda menos favorável ao negro. Este, nas poucas vezes em que aparecia na publicidade produzida no país, ocupava frequentemente, o espaço estigmatizado destinado à criadagem.

Mas foi exatamente naquele período que a publicidade de moda elaborada pelo italiano Lívio Rangan ${ }^{3}$ (diretor de publicidade da Rhodia Têxtil) e a equipe da Standard Propaganda introduziram pioneiramente imagens de modelos negras em suas campanhas veiculadas na mídia impressa (editoriais de moda, reportagens e anúncios impressos) como forma de agregar caracteres positivos às suas marcas (Tergal, Rhodianyl, Crylor, entre outras).

Para tentar entender essa decisão, em aparente descompasso com a realidade do mercado, analiso, aqui, campanhas veiculadas nas principais revistas de variedades e femininas nacionais então em circulação: Manchete, O Cruzeiro, Claudia e Jia.

A inserção das modelos negras em desfiles, editoriais e campanhas publicitárias no contexto da moda internacional e, sobretudo nos Estados Unidos, a partir do momento em que a segregação racial perde, naquele país, o status legal de que até então dispunha, impulsiona a participação de modelos negras brasileiras em peças publicitárias da Rhodia Têxtil, ainda que nessas publicidades tais modelos sejam apresentadas como representação de uma brasilidade calcada num sincretismo racial - definido como diversidade desprovida de conflitos e antagonismos (ORTIZ, 2006).

Pressupondo que "perante uma imagem, é nosso dever indagar qual a função que Ihe foi atribuída pelos responsáveis 
por sua composição" e observando que essas "pertenciam a um conjunto coerente de signos que historiador deve se esforçar para reconstruir" (DUBY, 1992), analiso textos e imagens que compõem os editoriais de moda, - que constituem "séries fotográficas" - produzidas pela equipe de publicidade da Rhodia Têxtil e divulgadas nas revistas O Cruzeiro, Manchete, Claudia e Jia entre 1960-1970. Observo que as modelos, e em especial as negras, colaboram na constituição dos "conjuntos coerentes de signos" representativos da brasilidade e na atribuem um status de vanguarda ${ }^{4}$ à moda divulgada pela referida publicidade. Privilegio o estudo do contexto da produção de tais fotografias, considerando-as "resultado de um processo de construção de sentido" que "fornece pistas para se chegar ao que não está aparente ao primeiro olhar, mas que concede sentido social à foto" (MAUAD, 1996, pp.83-84).

\section{A publicidade da Rhodia Têxtil e a profissão de modelo e manequim no Brasil dos anos 1960}

Até o início dos anos 1960, a produção jornalístico-publicitária de moda que encontramos no Brasil é muito incipiente. A maior parte das matérias veiculadas nas revistas era ilustrada com fotografias compradas de agências internacionais, como a UPI a Dalmas, como aqueles criados por Alceu Penna para $O$ Cruzeiro e A Cigarra.

Tal situação começa a mudar no final dos anos 1950, impulsionada por duas importantes transformações decorrentes da solidificação no país de uma sociedade de consumo ${ }^{5}$. A primeira delas é o início da profissionalização e estruturação do campo da moda, transformação que Fernando Novais e João Manuel Cardoso de Mello (2000) denominaram "revolução do vestuário". Ela se caracteriza pela introdução dos tecidos sintéticos no mercado (os quais barateiam significativamente o custo das vestimentas), massificação da produção de roupas ${ }^{6}$ e a segmentação, o crescimento e a renovação do mercado de revistas ${ }^{7}$ (ver MIRA, 1997). Nesta última área, presencia-se a criação, entre 1958-1961, de pelo menos três importantes 
periódicos femininos, Manequim (1958-/Abril), Jia (1958-1969/ Bloch) e Claudia (1961/Abril). ${ }^{8}$

Nesse contexto a Rhodia Têxtil ${ }^{9}$, então principal produtora dos filamentos sintéticos no país ${ }^{10}$, implementa uma política de publicidade calcada na produção de editoriais, reportagens e anúncios de moda para revistas femininas, além de variedades e desfiles, com o objetivo de conquistar o "segmento 'mais exigente' estabelecendo concorrência tanto com os tecidos brasileiros em fibras naturais como com os tecidos finos importados" (DURAND, 1985, p. 44). Para tanto, além de garantir sua fatia de mercado entre as confecções e indústrias têxteis, precisava conquistar o gosto dos brasileiros, vendendo com seu produto a idéia de que a empresa era responsável pela criação de uma "moda nacional" com qualidade internacional.

Conferir "brasilidade" aos seus produtos e marcas da Rhodia é um desafio que a empresa enfrenta utilizando os textos e imagens de suas peças publicitárias veiculadas na mídia impressa, e especialmente as fotografias difundidas em editoriais e reportagens de moda, carregados de signos de brasilidade. Esse efeito era alcançado através de recursos bem definidos: associação, especialmente através do cenário das fotos, entre alta moda e patrimônio histórico; exploração nas estampas das peças de roupas fotografadas das "riquezas naturais", exotismo e "motivos edênicos". Todos esses fatores convergiam para a "celebração", especialmente através da imagem das modelos, do sincretismo cultural e racial.

Como parte desse projeto de "invenção da moda brasileira" e seguindo o modelo da alta-costura ${ }^{11}$, Lívio Rangan cria um grupo fixo e exclusivo de manequins (cujo número variava entre quatro e nove) denominado "Seleção Rhodia Moda" para desfilar e fotografar as coleções confeccionadas com fios e tecidos da empresa. As mulheres que integravam o grupo atuavam como modelos nos desfiles realizados pela marca e também em reportagens, editoriais de moda e anúncios produzidos para diversas revistas nacionais, dentre as quais: Jia e Manchete (editora Bloch), Claudia, Manequim, Veja e Realidade (editora Abril) e A Cigarra e O Cruzeiro (Diários Associados). 
A intensa produção publicitária inscreve a empresa entre os maiores anunciantes da década de 1960. Nas revistas citadas, e em especial naquelas dedicadas ao público feminino, anúncios das marcas e produtos Rhodia são encontrados em quase todos os números. As participações publicitárias através de editoriais de moda aparecem em 20 números de Claudia (entre 19621970) e, em média, em 4 ou 5 das 12 edições anuais da revista Jia (entre 1964-1969). Em 1964, figuram em 7 dos 12 núme$\operatorname{ros}^{12}$

José Carlos Durand (1985) pondera que as novas revistas femininas surgidas entre o final dos anos 1950 e início dos 1960 eram basicamente "sustentadas pela publicidade das firmas têxteis, confecções e seus fornecedores" e em especial pela Rhodia Têxtil. Para Dulcília Buitoni (1981, p. 93), nesse período:

as revistas femininas trazem cada vez mais anúncios, a atestar a capacidade compradora de seu público. Mais páginas a cores, mais 'reportagens' de moda [...] o projeto editorial de cada veículo dirigido às mulheres tem em vista o consumo, em primeiro lugar. Contos, culinária, psicologia, conselhos de beleza não são escolhidos por si; tudo o que vai dentro de uma revista ou está ligado diretamente a um produto (moda, maquilagem, por exemplo), ou serve de atrativo para que a revista seja comprada e com isso divulgue a publicidade nela contida.

Nesse contexto, a frequente aparição das modelos da Rhodia nas revistas nacionais - e com menos assiduidade em outros veículos de comunicação, como jornal, cinema, outdoors e televisão, além dos desfiles de moda apresentados na Fenit (Feira Nacional da Indústria Têxtil) e em diversas cidades do país ${ }^{13}$ - permite considerá-las como as primeiras profissionais conhecidas por um grande público no Brasil.

\section{As modelos da Rhodia e o "Brazilian Look"}

Em texto elaborado para a exposição Metamorfose do Consumo, Cyro del Nero - cenógrafo dos shows da Rhodia e curador da exposição - relata: 
Diferente do que ocorre hoje, as manequins - numa faixa etária mais alta que a das manequins atuais - não ofereciam um time físico uniforme. Pelo contrário a diversidade era muito grande: Ully era germânica, Maylu era chinesa de Goa, Luana era negra, Geórgia, latino-européia. E Mila era um dos belos tipos de mulher do sincretismo brasileiro (NERO, 1999).

Para comprovar a afirmação, cita parte do poema "Seis manequins" (aqui reproduzido na integra), de Carlos Drummond de Andrade, escrito para o show de 1969 e no qual as diferentes belezas são festejadas:

Ully, Ully, Lullaby

Vou contigo para a lua Luarando vais levando Uma luz leve de linho De trigal maduro e lã. Maylu surge de repente E todos os véus da Ásia As arômatas do Egito As musicálias hindus Florescem na flor do ar. Ó Zula, que noite azul Clareia na tua pele Um mistério que escurece Quando tento decifrá-lo? Já se dilata a pupila Ante a passagem de Mila Que se pára ou se desfila Comove o sono da argila. E Nice, que vem da neve E da pelúcia mais suave Incenso, anjinho de nave Cantando na Lua Nova? Que não me falte Beatriz Jardim moreno de altura Para me fazer feliz No meu reino de aventura! (1992, pp. 1043-1044)

A observação da trajetória de algumas das mulheres que atuaram como manequins para a Rhodia permite concluir que a 
maioria delas tinha idades entre 18 e 20 anos quando se iniciaram na profissão (ver BONADIO, 2004), o que é um diferencial em relação à média etária atual das modelos iniciantes - que fica entre 12 e 13 anos (MARTINEZ, 2003) ${ }^{14}$. Já no que diz respeito ao tipo físico, é preciso relativizar as palavras do cenógrafo. A análise das séries de fotografias veiculadas em editoriais de moda e publicidades nas revistas mencionadas permite afirmar que a celebração do "sincretismo racial", através desse grupo de modelos, ocorre gradativamente nessas produções publicitárias, quase sempre respondendo à demanda do tema das coleções ou shows divulgados. Ainda assim, louras e morenas de pele alva predominam em relação às morenas de pele escura ou negras, não apenas em número, mas também em termos de visibilidade. Eram elas que, com maior freqüência, estrelavam as campanhas e figuravam nas capas das revistas ${ }^{15}$.

A primeira grande campanha publicitária da Rhodia, denominada "I Cruzeiro da Moda", foi veiculada nas revistas O Cruzeiro e A Cigarra entre os meses de agosto-outubro de 1960. Visava divulgar a "Linha Café", "uma coleção de 100 modelos com todos os detalhes da moda 1961 - do maiô ao vestido de gala - tudo confeccionado em tecidos e padrões nacionais" (O Cruzeiro, 1960, p. 136). Ainda que o texto da reportagem e as estampas criadas por artistas plásticos - em sua maioria inspiradas no café - buscassem relacionar a coleção, e mesmo as tendências internacionais da moda, à "cultura nacional", as modelos que compunham o grupo tinham tipo físico semelhante. Ainda que o tom de seus cabelos variasse entre o louro e o castanho escuro, eram todas brancas e longilíneas, num biótipo bem europeu. A reportagem, entretanto, frisa que a coleção apresentava a "diversidade do grupo": Sandra loura e esguia; Inge, intelectual e sorridente; a aristocrática Mariela e a linda gaúcha Lucia. (O Cruzeiro, 1960).

Entre 1960-1962, algumas modelos deixam o grupo e outras são incorporadas, mas os tipos físicos continuam os mesmos. Uma primeira "diversificação" acontece em 1963, quando, por ocasião da apresentação da coleção Brazilian Look ${ }^{16}$ (que excursionaria pela Itália, Portugal e Líbano), passam a integrar o time de manequins a morena Mila e a "oriental" Mailu, 
o que, para os padrões da época, era o máximo do exotismo e da diferença possíveis. A reportagem "Quando voam os manequins", publicada na Manchete (1963, pp. 64-66), ao traçar um breve perfil das modelos, apresenta Lílian como "encabulada", Lucia como "persistente", Mila como "caçadora contrafeita". A exemplo da matéria de $O$ Cruzeiro trabalhava a diversidade através da "personalidade", exceção feita a Mailu, sobre quem o texto dizia: "nasceu na China, foi registrada como portuguesa e tem um rosto lindo de linhas exóticas".

É possível que as manequins tenham sido foram convidadas a integrar o time em razão do nome da coleção e porque, de fato, a integração de Mila e Mailu à Seleção Rhodia Moda significava, em relação às moças que compunham o grupo anterior, um passo em direção ao almejado Brazilian Look. Ambas eram as modelos mais conhecidas do público e também as que integraram o grupo por mais tempo: ali permaneceram até 1970, quando a Rhodia mudou suas políticas publicitárias, reduziu os investimentos na divulgação da área têxtil e diminuiu consideravelmente a produção publicitária para esse segmento.

Em 1965, a equipe de publicidade da Rhodia pega carona na comemoração dos 400 anos da cidade do Rio de Janeiro e cria para a data o show "Rio 400 anos". Neste, "a moda carioca elegante e de carnaval e a música popular brasileira foram alegremente entrosadas" - informava Manchete. E acrescentava que "durante duas horas serão apresentados modelos criados por Alceu Penna, enquanto as platéias se deliciarão ouvindo na interpretação de bons artistas, uma antologia das melodias de Ari Barroso, em ritmo de bossa nova, pela dupla Mieli-Boscoli" (Manchete, 1964).

Criado pela Rhodia em pareceria com a revista Manchete, "Rio 400 anos" era patrocinado pelo Ministério das Relações Exteriores. Após a temporada carioca seria apresentado em Paris, Lisboa, Madri, Roma, Milão e Frankfurt. Nesse contexto, o Rio de Janeiro dá o tom do espetáculo e "a moda carioca e elegante de carnaval" é composta por figurinos de baianas e sinhazinhas estilizadas e criadas com inspiração nos desenhos de Debret. Esse também é o momento em que Sula, morena 
"jambo" de cabelos lisos, passa a integrar o time de manequins, provavelmente a fim de mostrar no exterior, o "corpo idealmente carioca", que segundo Fabiano Gontijo (2000, p. 51) seria "moreno, mas não negro".

A adequação, ainda que parcial, da aparência das modelos ao tema das promoções patrocinadas pela Rhodia se repete no ano seguinte. É o momento em que Luana, baiana e negra, passa a integrar o grupo. Segundo seu relato, ela foi descoberta em Salvador, por alguém da equipe de publicidade da Rhodia que estava na cidade buscando uma modelo negra para integrar o grupo em desfiles de moda que aconteceriam na Inglaterra, por ocasião da Copa do Mundo e cujo time de modelos deveria ser composto por todas as raças a fim de "representar a mulher brasileira"17.

Luana permanece por pouco tempo entre as modelos. Segundo seu relato, deixou o grupo no final de 1967, mas desde meados daquele ano não são registradas participações suas em editoriais de moda, anúncios ou fotos de desfiles. Daquele momento até meados de 1969, quando uma nova modelo negra (Zula) é incorporada ao grupo, louras e morenas, com tons de pele que variavam do branco ao moreno, voltam a ter exclusividade na publicidade da Rhodia Têxtil e, por via de conseqüência, nas páginas das revistas femininas e os editoriais de moda produzidos no Brasil.

\section{As modelos negras na publicidade da Rhodia e as modelos negras americanas: algumas aproximações}

[...] a manequim, com sua 'linha cabide' é um espetáculo dedicado a seduzir prioritariamente as mulheres como consumidoras e leitoras das revistas (LIPOVETSKY, 2000).

No Brasil dos anos 1960, os padrões de beleza e status ${ }^{18}$ dominantes e propagados pela mídia estavam longe de remeter à pele e ao biótipo negro. A veiculação de imagens dos negros na mídia impressa e audiovisual era restrita e estigmatizada ${ }^{19}$. A utilização de uma modelo negra como forma de sedução para as consumidoras era uma tarefa ousada e de difícil 
execução. Provavelmente por esse motivo, a inserção de Luana nas campanhas publicitárias da Rhodia foi feita de forma discreta e cuidadosa. Para entendermos melhor a situação brasileira, é fundamental observar que esse processo foi, em parte, consequência da participação bem sucedida de modelos negras na moda internacional e especialmente americana.

Em meados da década de 1960, as primeiras modelos negras começam a aparecer em capas de revistas e desfiles de moda internacionais. Mariuccia Casadio (2000) atribui ao estilista italiano Emilio Pucci o pioneirismo na escolha de modelos negras para desfilar no palácio de Pitti sua coleção outono-inverno 1964, dedicada à África.

Em janeiro de 1965, uma fotografia de Richard Avedon, da modelo negra Donayle Luna, ocupa a capa da Harpers Bazaar uma das mais importantes revistas de moda americana. Segundo Janice Cheddie, tal imagem pode ser considerada um momento histórico, um marco no mundo da moda e um importante avanço na luta dos direitos civis dos negros americanos. O poder aquisitivo dos consumidores negros já era conhecido dos publicitários daquele país em meados dos anos 1950, porém somente após o estrondoso sucesso do grupo The Supremes (composto exclusivamente por cantoras negras), a luta pelos direitos civis - que se intensifica em meados dos anos 1960 - e o fim da segregação racial em 1964 a situação irá se modificar. Com isso, o país passará de opressor a primeiro promotor do destaque para modelos negras na imprensa feminina (2002, p. 63).

Enquanto nos Estados Unidos é possível associar a abertura de espaço à ampliação do poder aquisitivo e especialmente à luta pelos direitos civis dos negros, no Brasil o espaço dedicado às modelos negras na publicidade e nas revistas de moda tem história diversa, diretamente conectada às políticas publicitárias da Rhodia nos anos 1960, ainda que possa ser considerado também um desdobramento indireto do sucesso de Donyale Luna - modelo que, além de alcançar grande sucesso na esfera da moda estadunidense, também ganhou status no mundo das artes a partir de suas participações em filmes experimentais dirigidos por Andy Warhol ${ }^{20}$. 
É possível relacionar a inserção de uma negra no grupo de modelos da Rhodia à repercussão da visibilidade de Donyale Luna. O codinome Luana, provavelmente escolhido Lívio Rangan (o verdadeiro nome da modelo era Simone Raimunda), tem grafia e sonoridade muito semelhantes ao sobrenome da modelo americana ${ }^{21}$. A hipótese ganha força quando se considera que ambas possuíam algumas características físicas semelhantes: nariz adunco, cabelo alisado, rosto comprido e formas longilíneas. Mas nem a aparência e nem o apelido que remetiam à modelo americana garantiram a Luana a mesma exposição privilegiada. Nas campanhas publicitárias, capas e editorias de moda sua imagem será mostrada ao público de forma gradual e cuidadosa.

Sua primeira aparição ocorre em junho de 1966, numa peça publicitária da Rhodia veiculada em diversas revistas nacionais, um anúncio de duas páginas sobre o lançamento da coleção Brazilian Fashion Team que tinha por tema a copa do mundo. Nos meses que antecederam o início dessa campanha publicitária, Donyale Luna ganharia ainda mais destaque: em março foi capa da edição britânica da Vogue, dessa vez, fotografada por David Bayle, e no mês seguinte foi tema de uma reportagem na revista Time denominada "The Luna Year", que proclamava:

Donyale Luna, $[\ldots]$ is unquestionably the hottest model in Europe at the moment. She is only 20, a Negro, hails from Detroit, and is not to be missed if one reads Harper's Bazaar, Paris Match, Britain's Queen, the British, French or American editions of Vogue. 'She happens to be a marvelous shape', says Beatrix Miller of British Vogue. 'All sort of angular and immensely tall and strange. She has a kind of bite and personality'22 (Time, 11 de abril de 1966).

No anúncio de divulgação da coleção Brazilian Fashion Team, as modelos fotografadas usam vestidos verdes com aplicação de letras em tecido amarelo e juntas formam a palavra Brasil. As duas primeiras modelos, cujos vestidos apresentam as letras B e R, estão em primeiro plano na foto; Luana aparece um pouco mais ao fundo, à esquerda de uma foto de Pelé - en- 
tão ídolo em ascensão e integrante da Seleção Brasileira de Futebol - vestindo a camisa da Seleção, estampada numa forma piramidal e atrás de várias bolas de futebol (Figura 1).23

A composição da referida imagem parece justificar a presença da modelo negra, que poderia ser considerada "deslocada" caso não estivesse diretamente associada ao futebol, e mais precisamente à seleção brasileira, que por aqueles tempos já era formada por vários negros, como o oniprsente Pelé.

Ao aproximar a então desconhecida modelo negra da imagem do jogador, a campanha utiliza recurso ainda hoje muito comum na publicidade: a associação de um produto a uma pessoa de sucesso. Estudos sobre os negros na publicidade concordam que a associação de produtos a jogadores de futebol, cantores e outros negros bem sucedidos "anulam" associação com a cor negra e frisam apenas o sucesso inerente à personalidade em questão (FRY, 2003; FARIAS, 2003 e BELELI, 2006), ou, como bem define o publicitário Guima, entrevistado por lara Beleli para sua tese de doutorado: "as pessoas não querem ser negras, as pessoas querem ser o Pelé e é com essa identificação que nós trabalhamos" (apud BELELI, 2006, p.98).

O cuidado com a inserção de Luana se repete na edição de julho de 1966 da revista Jia, cujo tema é a copa da Inglaterra e na qual são apresentadas todas as 150 peças da coleção Brazilian Fashion Team, num editorial de moda com 60 páginas. A capa da edição é confeccionada em página dupla, nas quais as modelos da Rhodia aparecem vestindo trajes estampados por artistas plásticos - em sua maioria nas cores da bandeira do Brasil (especialmente verde e branco) - ao lado de rapazes vestindo terninhos coloridos e portando instrumentos musicais, numa visualidade muito

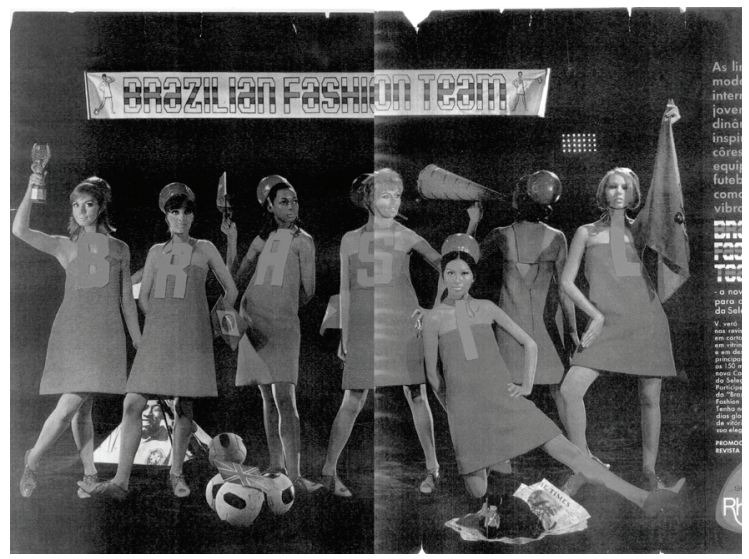

Figura 1 - Peça publicitária de divulgação da Coleção Brazilian Fashion Team. Jia, junho de 1966. 
próxima dos mods ${ }^{24}$ e dos Beatles. Na página principal, aquela que é vista pelo consumidor na banca de jornal, posam Ully, Mailu e Mila; Lilia, Crystia e Luana aparecem somente na página interna - aquela que a maioria dos consumidores só irá ver ao abrir a revista. Também na capa da revista, Luana não figura no primeiro plano, ficando mais uma vez atrás, e um pouco acima, do grupo principal (Figura 2).

No interior da revista, o texto Estria (breve) da coleo, explica: Brazilian Fashion Team, nascida em terra brasileira, perfumada de audácia, talento, experiências e individualidade - é cor e forma em expansão". O texto tem o cuidado de explicar que apesar de fotografada na Inglaterra - então principal centro de novidades da moda e cultura jovem - a campanha/a coleção foi criada no Brasil e temperada com "uma pimentinha especial - o futebol".

O verde e amarelo recebe destaque na coleção e surge não só nas modelos que aparecem na capa, mas também em outras apresentadas ao longo do editorial. Mas, se a "pimentinha especial" é o futebol nacional, não bastava apresentar modelos em verde e amarelo; assim, o texto explica: para divulgar essa "coleção bela, harmoniosa e tão variada usou-se um veículo fascinante: manequins de grande classe e beleza. Ully, Mailu, Mila, Cristya, Lilia e Luana num 'melting-pot' representando todas as raças que convivem no Brasil de hoje [...]" (Jia, julho de 1966).

$O$ texto seleciona significados aparentemente inerentes às

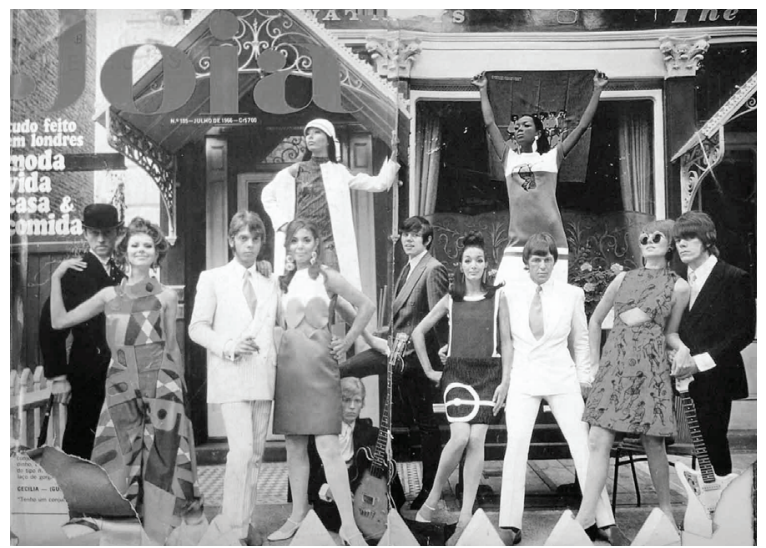

Figura 2 - Capa da revista Jia, julho de 1966. 
fotografias apresentadas nas páginas anteriores, ou nas palavras de Roland Barthes "o texto ilustra a imagem", ajuda a torná-la mais clara e legível, denotando-lhe "uma cultura, uma moral, uma imaginação" (1990, p. 20). Ou nas palavras de Grant McCraken: o texto "torna explícito o que já estava implícito na imagem", "fornecendo instruções sobre como a parte visual do anúncio deve ser lida" (2003, p. 108).

Apesar de o texto ressaltar a classe e a beleza das manequins e ser ilustrado com pequenas fotos dos rostos das modelos, Luana, no editorial propriamente dito, só aparece na quinta foto, depois que todas as demais modelos já foram "apresentadas" ao leitor. Ainda assim, sua presença necessita ser justificada através da construção da fotografia, na qual Luana é retratada ao lado de Lilia e três homens (dois deles negros), "típicos carregadores vindos das colônias inglesas", conforme a legenda (Figura 3).

Considerando que as legendas das fotografias "orientam a recepção num sentindo predeterminado, a contemplação livre não Ihes é adequada" (BENJAMIN, 1985, p. 79), podemos indagar até que ponto a apresentação de Luana ao lado de outros negros - os únicos que figuram nesse editorial de 60 páginas - não seria uma forma fortalecer a "justificativa" para a presença da modelo nas fotos, pois sua imagem estaria em consonância com parte da população londrina (ainda que aquela mais desfavorecida). Outro ponto que reforça a hipótese é o vestido usado por Luana em sua "estréia", um longo com estampa gráfica preto e branco, de Hércules Barsotti, em estilo Op-art que, numa primeira observação, salta aos olhos do observador e chama mais atenção que a modelo. $\mathrm{Na}$ maior parte das peças por ela usadas naquele editorial predominaram os motivos Op-art. A escolha do vestido com esse tipo de estampa poderia também ser outra referência à Donyale Luna, que havia aparecido nas páginas da edição de Abril de 1965 da revista Harpers Bazaar trajando um vestido

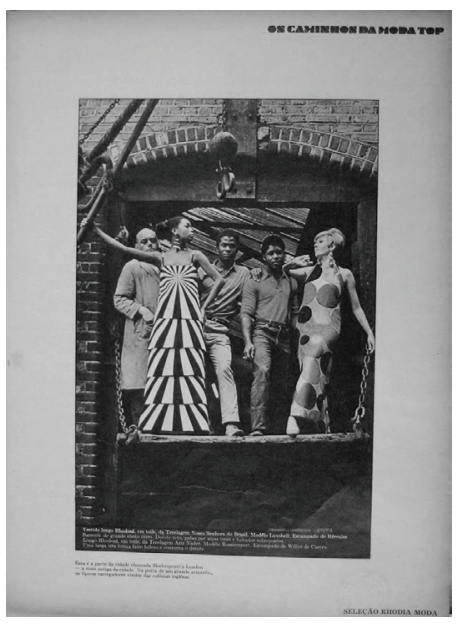

Figura 3 - Jia, julho de 1966. 


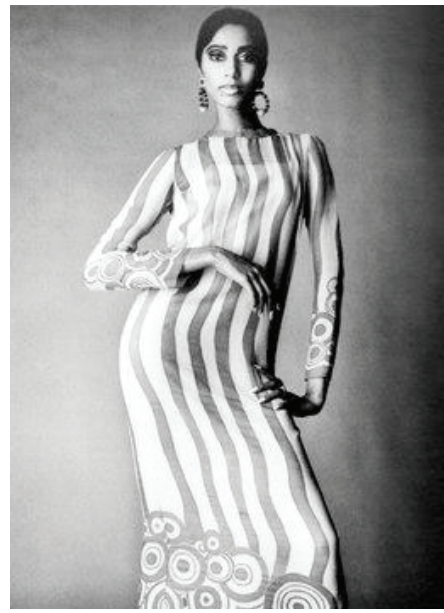

Figura 4 - Donyale Luna, Harpers Bazaar, Abril de 1965. Foto de Richard Avedon. no mesmo estilo (Figura 4).

Luana aparece outras vezes no editorial, mas somente em sua terceira inserção, à altura da vigésima página, é que posa sozinha, sem a companhia de outras modelos ou figurantes que, sem exceção, já haviam aparecido nessa situação. Isso nos leva a supor que seria necessário primeiro "acostumar" o olhar das leitoras à modelo negra - provavelmente a primeira do Brasil - para depois ampliar sua visibilidade na peça publicitária.

Também são reservados exclusivamente à modelo vestidos com estampas e cores inspirados em temas africanos, remetendo ao exótico. Exemplo dessa associação aparece numa fotografia na qual Luana traja um vestido estampado pelo artista plástico Carmélio Cruz, tendo ao fundo e em close a estátua de um leão ${ }^{25}$, recurso que reforça ainda mais a associação com o exótico e o "selvagem" $^{26}$ (Figura 5).

Em setembro, já apresentada ao público, Luana ganha mais destaque e figura ao lado de Mila e Mailu na primeira página do editorial que apresenta, na revista Jóia, a coleção prt--porter exibida inicialmente durante o September Fashion Show Esse evento realizou-se entre 21 e 25 de setembro de 1967 no Golden Room e MidNight do Copacabana Palace Hotel e teve por atrações desfiles do costureiro Castillo e da "Seleção Rhodia Moda". Nesse editorial, a modelo aparece em várias fotos. Nos meses que se seguem e até o início do ano seguinte, não são veiculados nessa e em outras revistas editoriais de moda elaborados pela equipe de publicidade da Rhodia Têxtil. Nos anúncios veiculados nesse período, não foi localizada a presença de Luana.

Em abril de 1967, quando finalmente a Rhodia volta a veicular na revista Jia um editorial de moda, Luana não está presente nas fotos. Sua última aparição nessas promoções acontece em junho do mesmo ano, no editorial "Decoração/Moda em 
contraponto" - também veiculado nas páginas de Jóia - mas a presença de Luana se restringe a uma foto e é sua última participação nos editoriais da Rhodia. Não se sabe a razão de sua aparição minguada, mas é provável que por esses tempos Luana já estivesse negociando sua saída do grupo para tentar carreira no exterior $^{27}$. É também possível aventar que uma modelo negra no contexto cultural brasileiro de meados dos anos 1960 não tenha agradado ao consumidor das camadas médias e altas mais refinadas, a quem provavelmente era direcionada a revista (BONADIO, 2005, ver cap. 3).

É na comemoração dos 50 anos da empre-

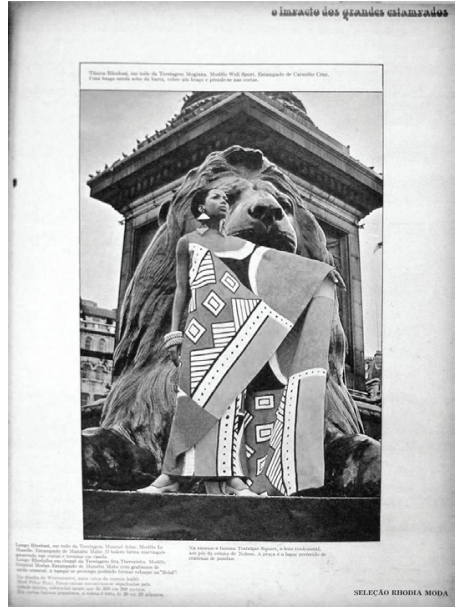

Figura 5 - Jia, julho de 1966. sa francesa no Brasil, em 1969, que uma nova modelo negra passa a integrar a equipe de modelos da Rhodia. É provável que Zula ${ }^{28}$ tenha sido especialmente contratada para integrar o "Seleção Rhodia Moda" na ocasião da realização do show Stravaganza (em agosto daquele ano), pois aparece pela primeira vez no editorial que registra a coleção veiculada pela revista Claudia em agosto de 1969.

A integração de Zula à "Seleção Rhodia Moda" possivelmente se dá em razão do desejo de imprimir uma marca forte e evidente de brasilidade - mais uma vez calcada na idéia do sincretismo racial - às marcas e produtos produzidos pela empresa de capital francês por ocasião da comemoração dos 50 anos de sua instalação no país. E também porque, em consonância com as transformações sócio-culturais que aconteciam no final dos anos 1960, a coleção Stravaganza celebrava a "diferença": apresentava roupas que subvertiam o "bom gosto" e as convenções (tais como mini-vestidos de noiva, ternos cor de rosa ou amarelo ovo para os homens e peças inspiradas na cultura cigana e no circo, misturando cores e padronagens), em fotografias nas quais as modelos dividiam a cena com malabaristas, palhaços, anões e outros tipos circenses.

No mesmo período, outro fator que provavelmente contribuiu para a incorporação dessa modelo foi o fortalecimento da 
popularização das modelos negras nas revistas de moda americanas e nos desfiles europeus. Na Time de 11 de abril de 1969, a reportagem Black Look in Beauty informava:

In recent months, for the first time in their history, Mademoiselle and Ladies' Home Journal have taken to using Negro as well as white models on their covers; black mannequins have appeared in almost every issue of Vogue and Bazaar for the past year. Of the 100-odd girls employed by the Ford model agency, New York's biggest and best known, a doz en now are black. Other formerly all-white agencies have similarly integrated their rosters, and in the past three months two new agencies have opened in Manhattan to handle black models. ${ }^{29}$

Na mesma reportagem, Eleanor Lambert, publicitária de moda conhecida como "a voz" da Sétima Avenida (uma das mais importantes ruas de moda em Nova York), decretava "this is the moment for the Negro girl." - referindo-se especialmente à Naomi Sims, a segunda modelo negra americana a alcançar sucesso internacional e ganhar as capas das revistas.

A partir de 1968, além de Donyale Luna e Naomi Sims, outras modelos negras ganhariam espaço em editoriais e desfiles de moda. Segundo Janice Cheddie, nos Estados Unidos "o maior impulso para a utilização de modelos negras surgiu em 1968, depois que foi criada a Comissão de Direitos Humanos de Nova lorque, que tratava diretamente do emprego de negros nas áreas de propaganda e divulgação, e da morte de Martin Luther King Jr" (CHEDDIE, op. cit, p. 69).

As transformações ocorridas nos Estados Unidos impulsionam uma maior aceitação das modelos negras em outros pontos do planeta, inclusive em Paris, onde inicialmente a oposição a esse grupo parece ter sido maior. A partir de 1969, Naomi Sims passa a realizar trabalhos para a alta-costura parisiense sem maiores problemas (CHEDDIE, op. cit.), um avanço se considerarmos que pouco antes, em 1964, o estilista Paco Rabanne, ao realizar um desfile apenas com modelos negras causou grande polêmica e enfrentou a reação negativa da imprensa (BAUDOT, 2000). Outro indício da resistência à integração das modelos negras no circuito parisiense de moda é a recusa da di- 
reção da Vogue Paris à sugestão de Edmonde Charles-Roux, então editora daquela publicação, de utilizar uma foto de Donyale Luna na edição francesa em $1966^{30}$. Uma evidência adicional dessa transformação é o gradual crescimento da participação de modelos negras em fotografias e desfiles de estilistas como Paco Rabanne, André Courrèges ${ }^{31}$ e Emanuel Ungaro ${ }^{32}$.

Colaborou para a maior aceitação das modelos negras o novo contexto artístico-cultural que emergia a partir da América do Norte entre 1968-1972, onde a soul music e um vasto movimento de emancipação dos negros propagam, em meio à loucura dos hippies, toda uma sensibilidade que mistura reminiscências africanas com padrões da cultura americana: Angela Davis ou James Brown, Diana Ross ou os Black Panthers. "Da cena do rock às manifestações políticas, da cabeleira afro às botas de plataforma, elabora-se todo um radicalismo chique que influirá na moda de lantejoulas da qual Elton John é a versão branca, gay e míope" (BAUDOT, op. cit., p. 226). É nesse período, de valorização da diferença - da qual a antimoda dos hippies $^{33}$ em termos de aparências é um dos principais exemplos - que muito do que até então era marginal ganhará (especialmente a partir de 1968) status de vanguarda e que as modelos negras obterão maior espaço na publicidade e eventos de moda ${ }^{34}$.

Talvez, o novo contexto internacional explique por que, apesar de não ter figurado em nenhuma capa de revista ou estrelado sozinha as peças publicitárias dos fios Rhodia, como Tergal, ou Rhodianyl - como acontecia com frequência com as outras modelos - Zula, aparece "naturalmente" nos editoriais de moda e catálogos dos shows-desfiles de 1969 e 1970³, ou seja, sem "explicações" ou "justificativas". Ela era, ou deveria ser, apenas mais uma modelo com potencial de despertar desejos de consumo nas leitoras das revistas.

\section{Considerações finais}

Nos últimos tempos, cresceu o número de estudos sobre a profissão de modelo e manequim (FARIAS, 2005; MARTINEZ, 
op. cit.; OLIVEIRA, op. cit.), um dos quais trata exclusivamente da condição das modelos negras brasileiras na contemporaneidade. Entretanto, ainda são exíguas as pesquisas sobre a história das representações atribuídas às modelos na publicidade e fotografia de moda. Neste artigo, a partir do pressuposto de que a publicidade "atua como potente método de transferência de significado, fundindo um bem de consumo a uma representação do mundo culturalmente constituído" (MCCRAKEN, op. cit., p. 106) e observando a centralidade das modelos na produção de significados sobre bens de consumo, procurei: a) mapear aquelas que provavelmente foram as primeiras participações de modelos negras em campanhas publicitárias de moda veiculadas em revistas de grande circulação no Brasil dos anos 1960; b) observar as condições ocorre a inserção dessas modelos e quais os sentidos atribuídos às e pelas modelos negras nas peças publicitárias analisadas.

O exame dos anúncios permite afirmar que a participação das modelos negras na publicidade da Rhodia Têxtil no Brasil, ainda que provavelmente pioneira, pode ser considerada efêmera, especialmente se levamos em conta o contexto internacional, no qual desde 1965 algumas modelos negras passam a figurar nas capas das principais revistas de moda e femininas, logo se inscrevendo entre as profissionais mais requisitadas e prestigiadas do período e derivando, dali, para a atuação nos circuitos das artes e do cinema.

As modelos da "Seleção Rhodia Moda" são bastante lembradas em biografias, livros e estudos acadêmicos sobre fatos e personagens da moda brasileira. Mesmo nesse material privilegiado, são raríssimas as menções a Luana e Zula ${ }^{36}$ e a participação daquelas profissionais nas campanhas da Rhodia é se revela sempre exígua. Não foram localizadas capas de revistas ou anúncios das marcas de fios e fibras produzidos pela empresa que hajam sido protagonizados exclusivamente por aquelas modelos. A participação de ambas nos editoriais de moda, como apontado anteriormente, também é bastante reduzida.

A presença de modelos de modelos negras na publicidade da Rhodia merece registro por significar uma exceção na publicidade de moda - e provavelmente em toda a publicidade 
nacional- dos anos 1960, mas é necessário perguntar como e por que tal participação ocorreu. As possíveis respostas para a questão foram buscadas no decorrer desta análise e é possível concluir que a referida inserção foi, antes de tudo, um recurso visando associar, aos produtos e marcas da empresa, um Brazilian look, uma imagem de brasilidade ligada à diversidade racial (e à convivência "harmoniosa"), que também enfatizava a uma pretensa "sintonia" da "moda brasileira" com as mudanças da moda internacional. Tal inserção não se relaciona com uma transformação proveniente de políticas destinadas a ampliar a visibilidade das mulheres negras na mídia ou democratizar as relações raciais através da publicidade, tanto que Luana e Zula (e todas as modelos americanas citadas no texto) são negras de traços ocidentalizados, ou seja, nariz e boca finos, e cabelos alisados.

\section{Notas}

1. Agradecimentos: Vavy Pacheco Borges e Geraldo Bonadio pelas sugestões e Aníbal Penna e Gabriela Ordones Penna pela cessão de imagens do acervo de Thereza de Paula Penna (in memoriam). Sobre as novas representações dos negros na publicidade, ver também BELELI (2006), especialmente o capítulo III.

2. A polêmica acerca da minguada participação das modelos negras na São Paulo Fashion Week resultou na assinatura de um Termo de Ajustamento de Conduta (TAC), firmado em maio de 2009, entre o Ministério Público e a organização do evento, que determina que ao menos $10 \%$ dos modelos de cada desfile devem ser negros, afrodescendentes ou indígenas. Ver <http://www.ipam.com.br/index.asp?LN=339\&VT=21> acessado em 24 de julho de 2009. A assinatura desse acordo, entretanto não encerrou o debate acerca da participação de modelos negras nas principais semanas de moda brasileiras. Durante a realização da 27ª São Paulo Fashion Week, em junho de 2009, a associação franciscana Educafro (Educação e Cidadania de Afrodescendentes e Carentes) organizou um desfile manifesto apenas com modelos negras na marquise do MAM (Museu de Arte Moderna), ao lado do prédio da Bienal, no Parque Ibirapuera (onde a São Paulo Fashion Week é realizada), com o de mostrar que não existe falta daquelas profissionais no mercado, como alegam habitualmente algumas pessoas ligadas às agências de modelos ou aos estilistas que integram as semanas de moda.<http://gazetaonline.globo.com/_conteudo/2009/06/101212-modelos+negras+f azem+protesto+por+cotas+no+sp+fashion+week.html> (acessado em 24 de julho de 2009).

3. O italiano Livio Rangan (1933-1984) chega ao Brasil em 1953 e, inicialmente atua como professor de latim do Colégio Dante Alighieri e repórter do Fanfulla. Em paralelo, organiza grandes espetáculos de ballet e passa a percorrer empresas em busca de patrocínio. Apresenta seus projetos à Rhodia, ganha a simpatia dos diretores da empresa e é contratado para atuar como gerente de publicidade, cargo que exerce até 1970.

4. Palavra aqui empregada no sentido de: Agente, grupo ou movimento intelectual, artístico ou político que está ou procura estar à frente do seu tempo, relativamente a ações, ideias ou experiências. Cf: http://www.priberam.pt/DLPO/default.aspx?pal=vanguarda> (acessado em 01 de novembro de 2009)

5. Sustentam os autores que esse processo "é caracterizado pela ampliação das indústrias 
de base, produtoras de matéria-prima para "quase tudo", em especial o aço e o petróleo; dos avanços na comercialização com o surgimento de supermercados, shopping centers, revendedoras de carros e redes de lojas de eletrodomésticos, tudo concorrendo para a massificação do consumo de novos produtos" (CARDOSO DE MELLO E NOVAIS, 2000, p. 75).

6.0 mercado do prt--porter, que então começa a emergir, encontra no Brasil, entre outras condições favoráveis, a popularização das fibras sintéticas e mistas, que ampliam e diversificam a produção de vestuário. A este cenário "juntou-se um mercado interno de roupas em crescimento rápido com sua posição alterando-se à medida que se expandiam, em efetivos e percentuais, as classes médias no conjunto da população e da força de trabalho. Enfim, um Brasil mais urbanizado, mais escolarizado, com classes médias mais amplas e de mulheres mais profissionalizadas ofereceu estímulo continuado àção industrial de roupas, à pesquisa de bens mais apurados e à renovação mais rápida de modelos". Tais condições favorecem a constituição do que, segundo José Carlos Durand, "hoje constitui o campo da moda" (Durand,1985, p. 36-55).

7. Renato Ortiz constata que, na primeira metade da década de 1960, o mercado nacional de revistas cresce de 104 milhões de exemplares vendidos ao ano, em 1960, para 139 milhões, em 1965. Colaboram para esse alargamento do mercado o crescimento demográfico, o aumento da taxa de alfabetização e a já citada ampliação das classes médias. A segmentação do setor e a atualização dos parques gráficos das principais editoras em atuação no país (Bloch e Abril) colaboram para modernizar a mídia impressa e as revistas tornam-se o principal veículo de divulgação da publicidade da Rhodia nos anos 1960 (ORTIZ, 1999, p. 122). Sobre os fatores que propiciam a ampliação e a modernização do mercado editorial de revistas, ver SEGUIN DES HONS (1985, pp. 125-161).

8. Jia foi lançada no mercado em 1958 e, até o início de 1963, era veiculada quinzenalmente. Circulou até 1969 e foi a principal revista feminina do grupo Bloch, ate 1969 quando, substituída pela revista Desfile, deixa de ser publicada.

9. Filial brasileira da francesa Rhône-Poulenc, instalada no pais desde 1919.

10. Em 1958, a Companhia Química Rhodia Brasileira, através de sua subsidiária Companhia Brasileira Rhodiaceta, obtém a exclusividade das patentes para a fiação, no Brasil, de fibras de poliéster, através de um acordo com a Imperial Chemical Industries, da Inglaterra. Até 1968 - quando se instala no país sua primeira concorrente de peso, a Safron Teijin, torna-se "um monopólio virtual sobre o segmento de produção das fibras sintéticas uma vez que produzia fibra de poliéster, filamentos de nylon 6.6, poliéster e fibras acrílicas (CORRÊA e MONTEIRO FILHA, 2002).

11. Até os anos 1960, era comum que cada casa de alta-costura tivesse um grupo exclusivo de modelos para seus desfiles e promoções (cf. EVANS, 2002).

12. Nos anos de 1962 e 1963, foram encontrados apenas 1 ou 2 editorias de moda da Rhodia divulgados na revista Jia.

13. Sobre esse tópico ver BONADIO (2005), especialmente capítulo 3.

14. Lucia Cúria tinha 22 anos quando passou a integrar a "Seleção Rhodia Moda"; Bettina Volk, 20; Bia Slivak, 18 e Ully Duwe, 19.

15. Exceção feita a Mailu, nascida em Goa, na Índia, e que em razão dos cabelos lisos, pele morena e olhos levemente puxados representava o tipo "oriental". Nas reportagens sobre o grupo de modelos veiculadas pela Rhodia, Mailu era identificada como chinesa.

16. Com vistas à associação da moda "nacional" à qualidade e tendências internacionais, coleções lançadas anualmente pela Rhodia Têxtil e veiculadas nas revistas femininas, em sua maioria, tinham seus nomes grafados em inglês, como Brazilian Look, Brazilian Style ou Brazilian Primitive. Apesar de soarem como "internacionais", tais nomenclaturas se utilizavam de palavras cognatas, ou já incorporadas ao vocabulário nacional, facilmente compreendidas pelos brasileiros das camadas médias - principal público-alvo da publicidade da Rhodia (BONADIO, 2005). 
17. No final de 1967, deixou a Rhodia e resolveu tentar carreira em Paris, onde em pouco tempo tornou-se modelo da agência Catherine Harley e passou a fazer fotos paras principais revistas de moda francesas e desfiles para costureiros como Courrèges e Paco Rabanne. Em razão do trabalho como modelo em Paris, passou a frequentar o jet-set internacional e casou-se com o conde Gilles de Noailles. Trabalhou até 1982 e até hoje vive em Paris. (cf. Claudia, 2004, p. 144-147).

18. Sobre os padrões de status social e raça no Brasil dos anos 1960, ver: Pereira (2001) e Schwarcz (2000); e sobre raça e publicidade ver FRY (2002).

19. É bastante conhecida a polêmica acerca da escolha do ator branco Sérgio Cardoso para interpretar o personagem principal da novela "A Cabana do Pai Tomás" (Excelsior, 1969). Para desempenhar o papel, o ator teve o corpo pintado de negro e usava rolhas queimadas no nariz e nos lábios para ganhar feições próximas às dos negros. Outro exemplo significativo dessa situação é a trajetória da atriz negra Ruth Cardoso, detentora de importantes prêmios no teatro, estreara na televisão numa novela da Record, em 1965, atuando como empregada doméstica. Em "A Cabana do Pai Tomás", ganhou o papel da esposa do protagonista, mas, segundo seus relatos para Joel Zito Araújo, aos poucos seu personagem foi perdendo importância em razão da insatisfação de algumas atrizes brancas que integravam o elenco da mesma telenovela. Ainda em relação à telenovela brasileira nos anos 1960, é relevante ressaltar as dificuldades encontradas pelo autor de "Vida em conflito" (Excelsior, 1969), na qual a protagonista, interpretada por Leila Diniz, casa-se com um homem negro, interpretado por Zózimo Bulbull. O script precisou ser alterado porque o público reagia negativamente ao tema (ARAÚJO, 2004). Em linhas gerais, além do papel secundário de empregada doméstica, durante os anos 1960, os poucos papéis reservados aos negros na telenovela brasileira eram os que reafirmavam os estereótipos do malandro carioca e da mulata sedutora e reforçavam o mito da "democracia racial" (ARAUJO, op. cit.).

20. Anteriormente à inserção da primeira modelo negra no grupo Seleção Rhodia Moda, Donyale Luna participou das seguintes produções de Andy Warhol: Screen Test: Donyale Luna, 1964 (16mm, preto e branco, 4 min, Coleção The Andy Warhol Museum, Founding Collection) e Camp, 1965. (preto e branco, $67 \mathrm{~min}$ ). Nos anos seguintes, participaria de diversos filmes, dentre os quais Qui tes-vouz Polly Magoo, 1967, dir. William Klein (preto e branco, França, $102 \mathrm{~min}$ ) e Satyricon, 1969, dir. Frederico Fellini (Technicolor, UK/USA, $128 \mathrm{~min}$ ). Para a filmografia completa da modelo, ver: <http://www.imdb.com/name/ nm0526021/> acesso em 13/08/2009.

21. Em entrevista para a revista Claudia, a ex-modelo, cujo nome verdadeiro é Simone Raimunda Nonato do Sacramento, relata que em 1966, ao desembarcar em Londres, a fim de posar para o editorial de moda que divulgaria a coleção Brazilian Fashion Team, "um jornalista inglês perguntou como se chamava. Ela já saiba que Simone Raimunda não iria funcionar. Respondeu sem pensar: 'Luana'. "E Luana ficou". (CLAUDIA, op. cit., p. 146) Outras modelos, que entrevistei para a realização de meu doutorado (BONADIO, 2005) afirmaram que, quando necessária, a escolha de apelidos, ficava à cargo de Lívio Rangan, que buscava através de tal recurso "melhorar o som" do nome das modelos. (BONADIO, 2004). Atribuído por Lívio, ou escolhido pela própria modelo, a proximidade do apelido, reforça a hipótese da busca por uma aproximação com a já famosa Donyale Luna.

22."Donyale Luna, [...] é inquestionavelmente a modelo mais quente na Europa nesse momento. Ela tem apenas 20 anos, é negra, de Detroit e não passa despercebida por quem lê Harper's Bazaar, Paris Match, Britain's Queen, e as edições britânica, francesa ou americana da Vogue. 'Ela tem uma silhueta maravilhosa' diz Beatrix Miller da edição britânica da Vogue. 'Angulosa e imensamente alta e estranha. Ela tem pimenta e personalidade.'" (tradução da autora)

23. No período Pelé era também, em razão de sua atuação no Santos Futebol Clube, o principal artilheiro do país

24. Mod é a denominação utilizada para definir uma subcultura jovem surgida em Londres no final dos anos 1950, cujo auge ocorreu em meados dos anos 1960 e que em termos 
de aparências se distinguiam especialmente através do uso de ternos coloridos e ajustados ao corpo.

25. Trata-se de um dos quatro leões adicionados em 1867 à coluna localizada na Praça de Trafalgar em Londres, construída entre 1840-1843 em homenagem ao Major Horatio Nelson, morto na batalha naval de Trafalgar em 1805.

26. Segundo Janice Cheddie "[...] a representação da mulher negra como símbolo animalístico e do primitivo continua a ser um constante quadro de referências nas revistas de alta-costura. A tensão entre o primitivismo exótico e a mulher burguesa continua a ressoar nas principais correntes da moda. Ao examinarmos a carreira da modelo inglesa Naomi Campbell nas décadas de 1980 e 1990, testemunhamos seu sucesso dividido entre a demanda da mulher burguesa e da primitiva exótica" (CHEDDIE, 2002, p.).

27. A modelo (hoje Condessa de Noailles) viaja a Paris em novembro de 1967 a fim de tentar carreira. A partir de 1968, ganha espaço nas principais revistas de moda francesa e passa a realizar trabalho para importantes estilistas (especialmente Paco Rabanne) até 1982, quando interrompe a carreira após ter engravidado (CLAUDIA, 2004, pp.144-147).

28. Se a primeira negra a integrar esse grupo tinha um codinome que soava a Lua e remetia a Donyale Luna, a nova modelo, com o codinome Zula, fazia referência direta à palavra 'zulu' que o dicionário Hoauiss define como: 1. indivíduo do povo zulu; . natural ou habitante da Zululândia, região histórica que é atualmente a província de Kwazulu; 3. língua banta da família nigero-congolesa do Sudeste da África, falada na República da África do Sul (área da antiga Zululândia), e tb. no Lesoto, Suazilândia e Maláui; zunda. Cf: http://houaiss.uol. com.br/busca.jhtm?verbete=zulu\&stype=k\&x=9\&y=8, acesso em 06/08/2009.

29. "Nos últimos meses, pela primeira vez na história, o Mademoiselle and Ladie's Home Journal vem apresentando tanto modelos negras quanto brancas em suas capas e manequins negras apareceram em quase todas as edições da Vogue e Bazaar no ano passado. De cada 100 garotas empregadas na agência de modelos Ford, a maior e mais conhecida de Nova lorque, uma dúzia agora é negra. Outras agências até pouco tempo exclusivamente "brancas" tem similarmente as tem integrado em seus castings, e nos últimos três meses duas novas agências foram abertas em Manhattan para abrigar modelos negras." (tradução da autora)

30. Episódio que teria levado ao pedido de demissão por parte de Edmunde Charles-Roux. Cf: Sangue Negro, São Paulo, 24 de julho de 2008, 16 h04. <http://74.125.113.132/search?q=cache:Ebwr71wPvMAJ:eu.spfw.com.br/noticia_det. php\%3Fc\%3D 1666+charles-roux+1966+donyale+luna\&cd=10\&hl=pt-BR\&ct=clnk\&gl=br>, acesso em 25 de julho de 2009.

31. Como se viu anteriormente, Luana afirma ter tido, a partir de 1968, uma bem sucedida carreira em Paris, onde realizou trabalhos para os estilistas Andre Courrèges e Paco Rabanne e fotografou para as revistas Elle e Vogue Paris (Cf. CLAUDIA, 2004, p. 145).

32. Não tendo sido encontrados trabalhos que mapeiem a participação das modelos negras no circuito da moda internacional nos anos 1960, a afirmação é baseada na pesquisa em livros que tratam da moda no período e trazem informações ou fotografias de peças produzidas pelos estilistas citados vestidas por modelos negras. Portanto, não é possível apontar se outros estilistas, além dos acima citados, teriam integrado negras aos seus grupos de modelos. (Cf. SELLING, 2000), ver também: <http://alejandrofrigerio.blogspot.com/2008_07_01_archive.html> acesso em: 05/08/2009.

33. Sobre o tema ver: GONÇALVES, 2007.

34. Ao longo da minha pesquisa de doutorado, não observei a participação de outras modelos negras em editoriais de moda produzidos no Brasil e divulgados nas revistas Claudia, Jia, A Cigarra, Manchete e O Cruzeiro.

35. Disque M para Moda, Jia, Agosto de 1969, aparece em 4 das 6 fotos do editorial. 
36. Em O Bordado da Fama: uma biografia de Dener, o autor Carlos Dória reserva uma breve nota sobre Luana ao glossário, a qual aqui reproduzo: "Uma das primeiras manequins negras do Brasil (junto com Zula) e das primeiras do mundo. Casou-se e vive na Itália" (DÓRIA, 1998, p. 197). As modelos não são citadas pelo livro "O Brasil na moda" organizado pelo empresário Paulo Borges (idealizador e diretor da São Paulo Fashion Week), que mapeia os principais personagens da moda brasileira desde os anos 1960 através de perfis e entrevistas. A ausência provavelmente se justifica em razão da pequena participação nas promoções da Rhodia e em outras campanhas e promoções da área da moda. O livro aponta Vera Lúcia Maria, conhecida por Veluma, como a primeira modelo negra a ganhar grande destaque no país e relata que, apesar de atuar em diversos trabalhos como desde o início dos anos 1970, só a partir de 1976 irá ganhar projeção nacional (Cf. BORGES, 2003, pp. 228-229).

\section{Referências}

\section{a. Fontes}

Estória (Breve) da coleção. Jia, n 155, julho de 1966.

A moda agora é Stravaganza,livre expressão no vestir jovem. In: Claudia, $n^{\circ}$ 95, agosto de 1969.

Memórias da condessa in: Claudia, n. 4, ano 43, abril de 2004.

Quando voam os manequins. In: Manchete, $n^{\circ}$. 568, 13 de julho de 1963.

Show de moda e bossa-nova. In: Manchete, janeiro de 1964 (sem data precisa, artigo pertencente à hemeroteca do acervo Thereza Penna).

The Luna Year. Time, 01 de abril de 1966. (disponível em: http://www. time.com/time/magazine/article/0,9171,840625-1,00.html, acessado em: 10/11/2008).

Black Look in Beauty. Time de 11 de abril de 1969. (disponível em http://www.time.com/time/magazine/article/0,9171,900763,00.html, acessado em 10/11/2008).

SAMPAIO, Paulo. "Mercado" é culpado por escassez de modelos negros no mundo da moda. In: Folha de S. Paulo, domingo, 20 de janeiro de 2008.

\section{b. Bibliografia}

ANDRADE, Drummond. Carlos. Seis manequins. In: Carlos Drumond de Andrade: e Prosa.

ANDRADE, Drummond Carlos (org.). Rio de Janeiro: Nova Aguilar, 1992 $8^{a}$. edição, pp 1043-44.

ARAÚJO, Joel Zito. A negao do Brasil: O negro na telenovela brasileira. Edição: 2a. São Paulo: Senac, 2004.

BARTHES, Roland. O bvio e o obtuso. Críticos III. Tradução: Lea Novaes. 
Rio de Janeiro: Nova Fronteira, 1990.

BAUDOT, François. Moda do sculo. Tradução: COSTA, Maria Thereza de Rezende. São Paulo: Cosac \& Naif, 2000.

BELELI, Iara. Marcas da diferena na propaganda brasileira. Tese de doutorado em Ciências Sociais, IFCH, Unicamp, 2006.

BENJAMIN, W. A obra de arte na era de sua reprodutibilidade técnica. In: Obras Escolhidas: Magia, Técnica, Arte e política. Tradução: ROUANET, Sérgio Paulo. Edição: 7ạ. São Paulo, Brasiliense, 1985, pp. 165-196.

BONADIO, Maria Claudia. Dignidade, celibato e bom comportamento: relatos sobre a profissão de modelo e manequim no Brasil dos anos 1960. In: Cadernos Pagu, jan/jun 2004 (22), pp.49-81.

O fio sinttico um show: Moda, política e publicidade (Rhodia S.A. 1960-1970). Tese de doutorado, Departamento de História, Instituto de Filosofia e Ciências Humanas, Unicamp, Campinas: 2005.

BUENO, Maria Lúcia e CASTRO, Ana Lúcia de (Orgs.). Corpo: Território da Cultura. São Paulo: Annablume, 2005.

BUITONI, Dulcília. Mulher de Papel: representação da mulher pela imprensa feminina brasileira. São Paulo: Edições Loyola, 1981.

CARDOSO DE MELLO, J. M. e NOVAIS, F.. Capitalismo tardio e sociabilidade moderna. In: SCHWARCZ, Lilia Moritz (Org.). Histria da Vida Privada no Brasil. Vol 4. São Paulo: Companhia das Letras, 2000.

CARRASCOSA, João (Ed.). O Brasil na moda: backstage. São Paulo: Editora Caras, 2003.

CASADIO, Mariuccia. Emilio Pucci (Coleção Universo da Moda). Tradução: Christina Murachco. São Paulo: Cosac \& Naif, 2000.

CHEDDIE, Janice. A política dos pioneiros: O emergir da modelo negra na era dos direitos civis. Tradução: PEREZ, Sérgio Bargo. In: Fashion Theory, São Paulo, vol 1, número 3, setembro 2002, pp 61-81.

CORRÊA, Abidack e MONTEIRO FILHA, Dulce Corrêa. BNDES: 50 anos Histrias Setoriais: O complexo txtil. Março de 2002. Disponível em: <http://www.bndes.gov.br/SiteBNDES/export/sites/default/bndes_pt/ Galerias/Arquivos/conhecimento/livro_setorial/setorial11.pdf > Acesso em 15, de julho de 2009.

DÓRIA, Carlos. Bordado da fama: Uma biografia de Dener. São Paulo: Senac, 1998.

DUBY, Georges (Dir). Imagens da mulher. Tradução: SILVA, Maria Manuela Marques. Porto: Afrontamentos, 1992.

DURAND, José Carlos. Vestuário, gosto e lucro. In: Cincias Sociais Hoje. Editora Cortez/ ANPOCS, 1985, vol. 1, pp. 36-55. 
EVANS, Caroline. O espetáculo encantado. Tradução: MORIYA, leda. In: Fashion Theory, São Paulo. volume 1, número 2, junho 2002, pp 31-70. FARIAS, Patrícia. Belezas negras à vista: presença negra na publicidade. In: TRAVANCAS, Isabel e FARIAS, Patrícia (orgs.). Antropologia e comunicao. Rio de Janeiro: Garamond, 2003, pp. 209-224.

FRY, Peter. Estética e política: Relações entre raça, publicidade e produção da beleza no Brasil. In: GOLDENBERG, Mirian (Org.). Nu \& Vestido: dez antropólogos revelam a cultura do corpo carioca. Rio de Janeiro: Record, 2002. GONÇALVES, Denise Oliveira. Avesso e Direito: movimento hippie e mercado cultural da moda.Uberlândia, Departamento de História da Universidade Federal de Uberlândia, 2007.

LIPOVETSKY, Gilles. A terceira mulher: ência e revolução do feminino.MACHADO, Maria Lúcia. São Paulo: Companhia das Letras, 2000.

MARTINEZ, Fabiana Jordão. O espelho de narciso: Corpos e textos do consumo. Dissertação de Mestrado, Departamento de Antropologia Social, Instituto de Filosofia e Ciências Humanas, Unicamp, Campinas: 2003.

MAUAD, Ana Maria. Através da imagem: fotografia e história interfaces. In: Tempo, Rio de Janeiro, vol. 1, no. E, 1996, pp. 73-98.

MCCRAKEN, Grant. Cultura \& Consumo:novas abordagens ao caráter simbólico e das atividades de consumo. Tradução: EUGÊNIO, Fernanda. Rio de Janeiro: MAUAD, 2003.

MESQUITA, Letícia Nassar Matos. Uma diagramação sedutora: a construção da identidade gráfica da revista Nova. In: Anais do V Encontro dos Núcleos de Pesquisa da Intercom (Congresso Brasileiro de Ciências da Comunicação), Rio de Janeiro/UERJ, 2005. <http://www.intercom.org.br/papers/nacionais/2005/resumos/R1073-1.pdf> (acessado em 22 de julho de 2009).

MIRA, Maria Celeste. O leitor e a banca de revistas: o caso da Editora Abril. Doutorado em Sociologia, IFCH, Unicamp, 1997.

NERO, Cyro del. Metamorfoses do consumo. In: BORGES, Adélia. Paratodos. Catálogo da Exposição Arte/Consumo. São Paulo: Itaú Cultural, 1999. disponível em <www.itaucultural.org.br> acesso em 11/08/2009.

OLIVEIRA, Ana Carolina Delgado de Oliveira. Novas imagens, velhos conceitos a produo de imagens de moda no Brasil e a visibilidade dos modelos negros. Dissertação de mestrado em sociologia e Antropologia, IFCS, UFRJ, 2007.

PEREIRA, João Baptista Borges. O negro e o rdio de So Paulo. Edição: 2ạ . São Paulo: Edusp, 2001.

SCHWARCZ, Lilia Moritz. Nem preto nem branco, muito pelo contrário: cor e raça na intimidade. In: SCHWARCZ, Lilia Moritz (Org.). Histria da Vida 
Privada no Brasil. Vol 4. São Paulo: Companhia das Letras, 2000, . 559-658. SEGUIN DES HONS, André de. Le Brèsil: presse et historie 1930-1985. Paris: L'harmattan, 1985.

SELLING, Charlotte. Moda: O século dos estilistas 1900-1999. Tradução: Letrário. sl, Konemann, 2000.

\section{Crédito das imagens:}

Figuras 1, 2, 3 e 5 (Acervo Thereza Penna)

Figura 4: (disponível em: <http://lipsticklacebrassknuckles.wordpress.com /2008/02/21/donyale-lunathe-first-black-model/>acesso em 05/08/2009).

\section{Maria Claudia Bonadio}

Maria Claudia Bonadio é bacharel, mestre e doutora em História pela Unicamp; professora e pesquisadora do Centro Universitário Senac na área de Design de Moda. Autora do livro "Moda e Sociabilidade: mulheres e consumo na São Paulo dos anos 1920" e membro do Conselho Editorial das revistas Dobra[s] e lara: Revista de moda, cultura e Arte.

E-mail: mariacbonadio@uol.com.br 